\title{
Enantioselective Minisci-Reaction of N-Heterocycles and Amides through Hydrogen-Atom Transfer
}

Organo- and

Biocatalysis

\section{Key words}

Minisci reaction

hydrogen-atom

transfer

aza-heterocycles

phosphoric acids<smiles>NC(=O)CO</smiles>

5-10 mol\% (R)-CPA 10-20 equiv diacetyl

$t$-BuOAc, Kessil Tuna Blue, r.t. 24-48 h

$=\mathrm{Me}, \mathrm{OMe}, \mathrm{Cl}, \mathrm{CN}, \mathrm{CO}_{(2)} \mathrm{Alk}$

$=\mathrm{Bn}$, Alk, $\mathrm{CO}_{2} \mathrm{Alk}$

Proposed mechanism:

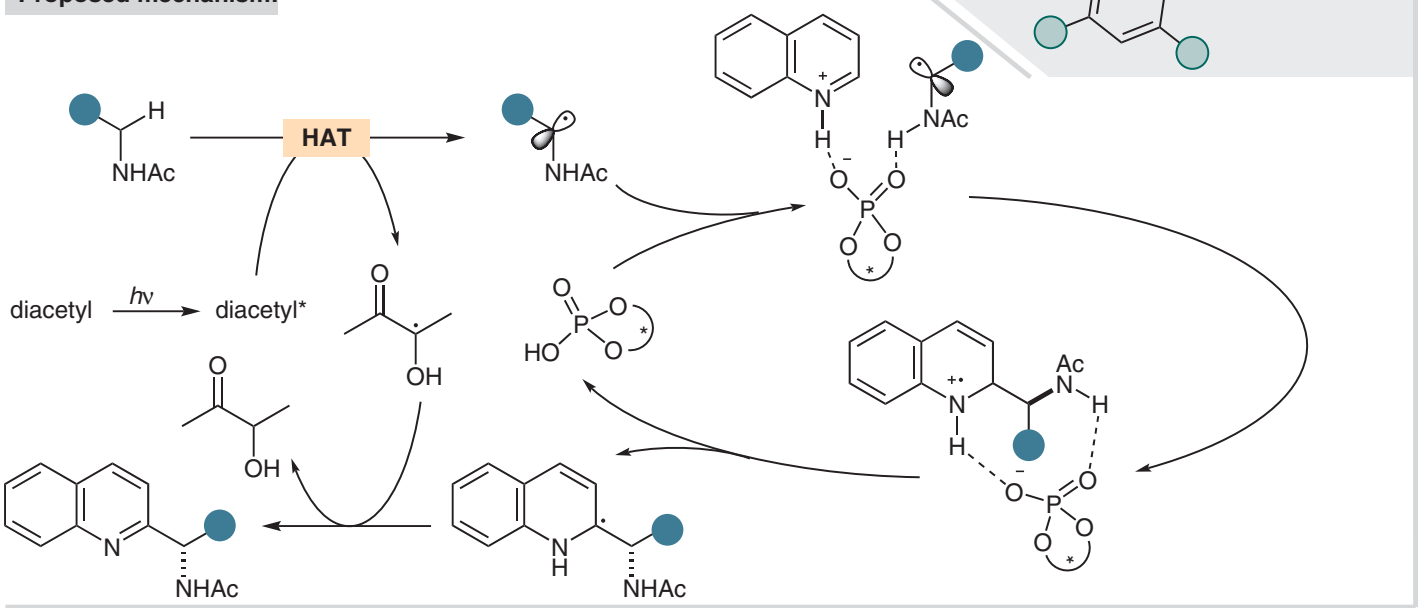

Selected examples:<smiles>Cc1cc([C@@H](NC(N)=O)C(C)C)nc2ccccc12</smiles>

$55 \%$ yield er $=98.5: 1.5$

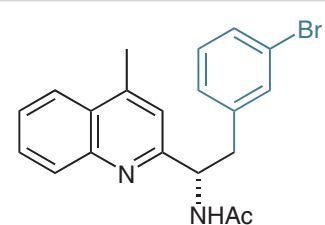

$61 \%$ yield er $=97: 3$

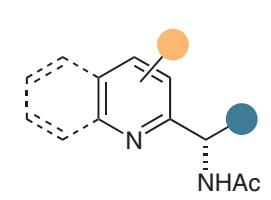

27 examples yields from $32 \%$ to $85 \%$ er from 89.5:10.5 to 99:1<smiles>C/C=C\C=C/C=C/C</smiles><smiles>OCC1CCC2CCC1O2</smiles>

(R)-CPA

(R)-TRIP

$O=i-\operatorname{Pr}$

(R)-TCYP $\mathrm{O}=\mathrm{Cy}$
Significance: Phipps and co-workers report a photochemical hydrogen-atom transfer (HAT)-driven enantioselective Minisci reaction of N-heterocycles with amides by using one of a series of chiral phosphoric acids as the chromophore and diacetyl as the terminal oxidant. The corresponding C2-substituted products are obtained in moderate to good yields and with good to excellent enantioselectivities.



Comment: On the basis of their recent experimental and theoretical investigations (J. Am. Chem. Soc. 2020, 142, 21091), the authors address several limitations, including the laborious synthesis of redox-active esters and low-yielding reactions. The successful introduction of easily accessible $\mathrm{N}$-acylated primary amines as sources of $\alpha$-amino radicals led to the establishment of a more generally applicable system with a broad substrate scope, with diacetyl as an inexpensive chromophore and chiral phosphoric acids to induce enantioselectivity. 